\title{
Killers 2.0: NK cell therapies at the forefront of cancer control
}

\author{
Jonathan J. Hodgins, ${ }^{1,2}$ Sarwat T. Khan, ${ }^{1}$ Maria M. Park, ${ }^{1,2}$ Rebecca C. Auer, ${ }^{1,3}$ and Michele Ardolino ${ }^{1,2}$ \\ ${ }^{1}$ Centre for Cancer Therapeutics, Ottawa Hospital Research Institute, Ottawa, Ontario, Canada. ${ }^{2}$ Department of Biochemistry, Microbiology and Immunology, and ${ }^{3}$ Department of Surgery, \\ University of Ottawa, Ottawa, Ontario, Canada.
}

\begin{abstract}
Natural killer (NK) cells are innate cytotoxic lymphocytes involved in the surveillance and elimination of cancer. As we have learned more and more about the mechanisms NK cells employ to recognize and eliminate tumor cells, and how, in turn, cancer evades NK cell responses, we have gained a clear appreciation that NK cells can be harnessed in cancer immunotherapy. Here, we review the evidence for NK cells' critical role in combating transformed and malignant cells, and how cancer immunotherapies potentiate NK cell responses for therapeutic purposes. We highlight cutting-edge immunotherapeutic strategies in preclinical and clinical development such as adoptive NK cell transfer, chimeric antigen receptor-expressing NK cells (CAR-NKs), bispecific and trispecific killer cell engagers (BiKEs and TriKEs), checkpoint blockade, and oncolytic virotherapy. Further, we describe the challenges that NK cells face (e.g., postsurgical dysfunction) that must be overcome by these therapeutic modalities to achieve cancer clearance.
\end{abstract}

\section{NK cells: sentinels against cancer}

The existence of immune cells that mediate cellular cytotoxicity without prior activation was determined by multiple groups who reported the spontaneous killing of tumor cells by lymphocytes from unimmunized mice (1-3). We now know that these cells with natural cytotoxicity, or natural killer (NK) cells, are important mediators of cancer immunosurveillance. NK cells are a heterogeneous population, and in humans they have been historically divided into IFN- $\gamma$-producing $\mathrm{CD} 56^{\text {hi }} \mathrm{CD} 16^{+}$and cytotoxic $\mathrm{CD} 56^{\text {lo }} \mathrm{CD} 16^{\text {hi }}(4)$, whereas in mice they are grouped according to their expression of CD27 and CD11b (5), although it is now clear that the complexity is much higher. Distinct NK cell subsets play different roles in tumor immunity and cancer immunotherapy, as reviewed in Stabile et al. (6).

NK cells are equipped with many receptors that tightly regulate their activation and allow them to discriminate between "normal" and "dangerous" cells (7). In addition to regulating NK cell activation, signals coming from activating and inhibitory receptors also tune the steady-state responsiveness of NK cells to future stimuli, in a process called NK cell education (reviewed in refs. $8,9)$. Inhibitory receptors, such as killer-cell immunoglobulinlike receptors (KIRs), deliver negative signals that prevent NK cell autoreactivity. KIRs and other inhibitory receptors recognize MHC I molecules, whose absence may result in NK activation, the so-called "missing-self recognition" $(10,11)$. Later studies showed that lack of MHC expression was not sufficient or necessary to

Authorship note: JJH and STK equally contributed to this manuscript.

Conflict of interest: RCA is a coinventor in a patent (international publication number W02018027316A1, application number PCT/CA20 17/050941) submitted for an IL-12armed oncolytic virus.

Copyright: (c) 2019, American Society for Clinical Investigation.

Reference information: J Clin Invest. 2019;129(9):3499-3510.

https://doi.org/10.1172/JCl129338. induce NK activation; rather, signaling from activating receptors was required. Broadly speaking, activating receptors, including NKG2D, provide activating signals upon binding to stress-induced ligands on target cells, which is referred to as "induced-self recognition" $(12,13)$. Ultimately, NK activation depends on the balance between activating and inhibitory signals triggered by these receptors binding their ligands. When activating signals prevail, NK cells respond, whereas when inhibitory signaling is stronger, NK cells do not respond. Healthy cells, with some exceptions (1416), express low levels of activating ligands and an abundance of inhibitory ligands and therefore are not attacked by NK cells. On the other hand, tumor cells often acquire expression of NK cellactivating ligands and/or lose expression of MHC molecules. NK cells sense and respond to changes in the repertoire of molecules expressed on the surface of healthy cells during cellular transformation. This positions NK cells as important sentinels against cancer and as prime targets for cancer immunotherapy (17).

\section{NK cells in cancer immunosurveillance}

Despite their potent antitumor activity, NK cells face substantial challenges that hinder their efficacy. Several studies have shown that tumor-infiltrating human NK cells have altered expression of inhibitory and activating receptors and impaired functions (18-20). Many mechanisms mediate NK cell suppression in the tumor microenvironment, several of which also contribute to dampening of $\mathrm{T}$ cell responses. Reviewing these mechanisms is beyond the scope of this work, and has been done elsewhere (17). However, one NK cell-regulating process that has attracted much attention is the release of soluble NKG2D ligands. NKG2D ligand release occurs either by shedding, which is mediated by extracellular proteases, or by exosomal secretion $(21,22)$. Soluble NKG2D ligands engage NKG2D on NK cells, preventing their interaction with membrane-bound ligands on tumor cells that would produce a cytotoxic response (22). Therapeutic targeting of NKG2D-ligand 
shedding proved successful in preclinical studies (23). However, soluble NKG2D ligands have also been shown to promote NK cell antitumor activity, as in the case of soluble MULT1, which prevented NK cell desensitization in mouse models of cancer (24). These results suggest a context-dependent function of these soluble molecules and warrant more investigation.

The tumor microenvironment contains large amounts of immunosuppressive cytokines and other soluble factors that affect NK cell functionality, with one of the most prominent being TGF- $\beta$ (25). In addition to inducing downregulation of surface NKG2D, resulting in decreased cytotoxicity (26), TGF- $\beta$ has been shown to be able to alter cytotoxicity, cytokine production, metabolism, and mitochondrial function in NK cells (27-29). Recent studies proposed that TGF- $\beta$ also converts NK cells into noncytotoxic group 1 innate lymphoid cells (ILCs), allowing for tumor growth and metastasis in mice $(30,31)$.

Despite the immunosuppressive environment of solid tumors, NK cell activity/infiltration has been correlated with improved prognoses in humans. Rate of local recurrence following surgical tumor resection of colorectal cancer correlated with lower NK cell levels (32). Correlations between reduced NK cytotoxicity and incidence of metastasis have been established in head and neck as well as pharyngeal cancer (33-35). In gastrointestinal sarcoma, NK cell infiltration negatively correlates with metastases (20). Additionally, improved survival has been correlated with NK infiltration in lung metastases of renal cell carcinoma patients (36). These examples highlight the potential for NK cell immunotherapies to improve patient outcomes.

\section{NK cells in conventional cancer treatments}

The longstanding anticancer strategies chemotherapy and radiotherapy are now known to mediate their effects, at least partially, via the immune system. Both chemo- and radiotherapy induce cellular stress in tumor cells, leading to upregulation of NK-activating ligands, release of damage-associated molecular patterns (DAMPs), and induction of immunogenic cell death (37-39).

Through different mechanisms, genotoxic agents, HSP9O inhibitors, histone deacetylase (HDAC) inhibitors, glycogen synthase kinase 3 (GSK-3) inhibitors, and proteasome inhibitors can all increase tumor surface expression of NK-activating ligands (40-43). Several chemotherapeutics downregulate the NK inhibitory ligands MHC I and Clr-b on tumors to promote missing self recognition $(44,45)$. Effects on NK recruitment and activation were also observed with several chemotherapeutics. For example, in mouse models, successful tumor clearance following treatment with DNA-alkylating agents required recruitment of neutrophils and NK cells (46). Recently, MAPK and CDK4/6 inhibitors were shown to promote NK-mediated tumor clearance (47). DNA damage induced by ionizing radiation has effects that are similar to those of chemotherapeutics. DNA damage from high-dose radiation and chemotherapy both led to increased expression of NKG2D ligands through an ATM- and ATR-dependent pathway (48). The exact mechanisms of action induced by each chemoand radiotherapeutic agent discussed here are unique, and newer pathways are constantly being targeted to enhance responses, which led to a renewed interest in exploiting chemotherapy and radiotherapy as immune-modulating modalities.
Surgical resection is still the predominant curative treatment modality for many solid malignancies, but, surprisingly, the immune-modulatory effects of surgery have been understudied. Increased metastatic disease or recurrence following surgery has been widely observed in humans and recapitulated in animal models (49). In addition to unintentional mechanical dissemination and altered proliferation and signaling in tumor cells, it is now clear that surgery compromises NK cell functions, providing an opportunity for tumor spread and growth (49-54). Several mechanisms contribute to NK cell dysfunction following surgery, including soluble inflammatory mediators and immunomodulatory cells such as myeloid-derived suppressor cells (MDSCs), which arise by emergency myelopoiesis following surgery (49-51).

In conclusion, NK cells play a fundamental role in traditional cancer treatments, and further research is needed to ameliorate their efficacy following chemo/radiotherapy as well as surgery.

\section{Adoptive NK cell therapy}

Allogeneic NK cells. One of the most striking examples of the anticancer functions of NK cells comes from missing self recognition. Hematopoietic stem cell transplantation (HSCT) is an effective and curative treatment option for acute leukemia patients. Allogeneic HSCT relies on HLA matching between donor and recipient to avoid graft-versus-host disease (GVHD). In the absence of an HLA-compatible donor for allogeneic HSCT, HLA-haploidentical HSCT, whereby the recipient shares only one HLA haplotype with the donor (often a parent), is performed. A series of pioneering studies showed that in haplo-HSCT, recipients whose HLA molecules were mismatched with donor KIRs had less relapse after transplant, indicating a potent NK-mediated graft-versus-leukemia (GvL) effect, whereas KIR mismatch was not found to cause GVHD (55-57). The contribution of NK cells in HSCT has been comprehensively reviewed previously $(58,59)$, with discussions on how to select recipient-donor pairs in order to enhance NK cell alloreactivity and transplant outcomes that are currently ongoing $(9,60)$. While T cells play a critical role in the efficacy of HSCT, this example highlights the often-overlooked contribution of NK cells to antitumor immunity.

The impressive GvL effect generated by KIR-mismatched NK cells in haplo-HSCT spurred hematologists to explore infusions of highly purified haplo-identical NK cells to increase GvL. Clinical trials reported complete remissions in elderly acute myeloid leukemia (AML) patients $(61,62)$, as well as $100 \%$ event-free survival in a pediatric AML cohort with 18 months follow-up (63). In multiple myeloma (MM), encouraging results from a phase I trial where patients received cord blood-derived KIR-mismatched NK cells prior to HSCT (64) led to an ongoing phase II study (NCT01729091).

Autologous NK cells. Autologous NK cells have also been explored for cancer immunotherapy, although this field is less advanced than for autologous T cell transfer. While NK cells can be isolated and ex vivo expanded from the peripheral blood of patients, NK expansion has proven more troublesome than $\mathrm{T}$ cell expansion. Clinical trials have not observed clinical responses with autologous NK cell infusion, despite successful NK engraftment and persistence in peripheral blood $(65,66)$. However, the functional status and expansion of the autologous NK cells is 
often poor (67). This could be due to the treatments received by the patients before NK isolation, which may also explain their poor clinical efficacy. Multiple approaches are being investigated to overcome this issue, including different combinations of activating cytokines (IL-2, IL-12, IL-15, IL-18) and the use of feeder cells to supply important factors during ex vivo expansion (17). To this end, a phase I trial in MM using autologous NK cells activated by a feeder cell line expressing membrane-bound IL-15 and 4-1BBL resulted in modest clinical activity (68), which suggested it may be possible to optimize feeder cells to improve NK activation before adoptive transfer (69). Additionally, studies have shown that autologous NK cells are more effective when tumor cells lack at least one HLA ligand for the KIR expressed by the transferred NK cells ("missing ligand" hypothesis) $(70,71)$.

Off-the-shelf NK cells. Given the difficulties of sourcing abundant numbers of cytotoxic NK cells from peripheral blood, additional strategies have been investigated to provide readily available banks of NK cells for patients. The human cell line NK92, widely used for preclinical applications, has been clinically investigated as an allogeneic NK therapeutic. One clinical trial involving 15 advanced lung cancer patients observed encouraging responses (72), but clearly much research is needed to carefully validate the safety profile of NK92 cells as a cancer therapeutic.

NK cells can be differentiated from stem cells, both induced pluripotent stem cells (iPSCs) and those obtained from umbilical cord blood. iPSC-derived NK cells have been shown to have high cytotoxicity against tumors of various origin, both in vitro and in vivo (73-75) and clinical trials have commenced using expanded cord blood-derived NK cells. More recently, an effort to derive NK cells from iPSCs generated from peripheral blood cells has been made. NK cells derived from peripheral blood iPSCs show low KIR expression and a promising capacity to perform both cellular cytotoxicity and antibody-dependent cellular cytotoxicity (ADCC) against cancer cell lines in vitro (76). While these findings await in vivo corroboration, peripheral blood represents an attractive alternative source of iPSCs, as cord blood is still rare and difficult to recover.

CAR-NK cells. A promising avenue in adoptive NK therapy is the use of chimeric antigen receptors (CARs). A CAR, usually encoded in a lentiviral construct, consists of three main domains: an extracellular antigen-targeting domain (ectodomain), a transmembrane region, and one or more intracellular signaling domains. Specificity for targets is conferred by the ectodomain, which is reactive against a tumor-specific or tumor-associated antigen (e.g., CD19, CD20, CD22, Her2, ROR1) (77). CAR-T cells have shown remarkable responses particularly in $\mathrm{B}$ cell malignancies, which led to FDA approval in non-Hodgkin lymphoma and diffuse large B cell lymphoma $(78,79)$.

Given the success of CAR-T cells, CARs are now being used to potentiate NK antitumor activity. Currently, there are 14 listed trials for CAR-NKs on ClinicalTrials.gov (as of July 10, 2019) (Table 1 ), with the majority of the trials focused on leukemia. One of these trials showed that CD33-targeting CAR-NKs were safely administered to patients with relapsed or refractory AML, albeit with limited clinical efficacy (80). The authors speculated that reduced longevity and cytotoxicity of irradiated (for safety) CAR-NKs were potential pitfalls and noted that efficacy might only be achievable when used to treat malignancies with a slower disease progression.
Preclinical studies continue to explore strategies to enhance CAR-NK efficacy, such as changing the CAR intracellular domains. Historically, the $\mathrm{CD} 3 \zeta$ chain has been used alone or in combination with $\mathrm{CD} 28,4-1 \mathrm{BB}$, or OX40 signaling domains (77). Although these costimulatory domains were designed to promote $\mathrm{T}$ cell responses, they also activate NK cells (81). More recently, the signaling domains of adaptor molecules associated with activating NK receptors were used to mimic physiological NK signaling and, remarkably, a CAR-NK with the DAP12 intracellular domain exhibited enhanced cytotoxicity compared with a

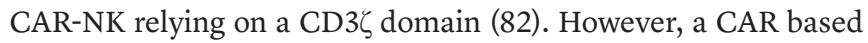
on DAP10 motifs performed poorly when used as the sole signaling domain (83). More encouraging results were obtained using an

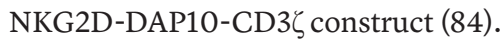

While most of these studies explored a few closely related CAR-NK constructs, $\mathrm{Li}$ et al. conducted a comprehensive screen and found that a $2 \mathrm{~B} 4$ costimulatory plus $\mathrm{CD} 3 \zeta$ intracellular signaling domain mediated better specific cytotoxicity than other combinations of $\mathrm{CD} 3 \zeta$, DAP10, DAP12, CD28, 2B4, and CD137 domains (85). As the field continues to expand, a better understanding of what dictates efficacy of different CAR constructs in various situations will likely follow.

Adoptive NK cell transfer, with or without a CAR, may provide a safer and more feasible alternative or, at the very least, an addition to $\mathrm{T}$ cell-based approaches. In fact, whereas allogeneic CAR-T cells are currently not an option due to the risk of GVHD, allogeneic NK cells are safe in this regard. This allows for the use of more readily accessible NK sources to engineer using CARs, such as cell lines (NK92, KyHG1) or allogeneic NKs derived from cord blood or iPSCs $(81,85-87)$. Use of allogeneic sources can pave the path for CAR-NKs to eventually become off-the-shelf therapies, whose safety can be substantially increased by the possibility of including suicide genes (88). Finally, whereas CAR-T cells become ineffective if tumor cells downregulate the CAR antigen (89), CAR-NKs would still recognize tumors through their germline-encoded receptors, reducing the chances of tumor escape through antigen modulation. Overall, CAR-NKs have the potential to become a safe and practical addition to the immunotherapy arsenal.

In conclusion, the numerous ongoing clinical trials employing autologous or allogeneic NK cells for a variety of indications hold great promise. NK cell transfer could complement, and in some scenarios substitute for, $\mathrm{T}$ cell-based adoptive transfer therapies to maximize antitumor effects and reduce treatment toxicity.

\section{Cytokine therapy: mobilizing NK cells in cancer}

One major disadvantage of an adoptive transfer approach is the high costs and expertise required to manufacture large amounts of clinical-grade immune cells $(81,90)$. For this reason, off-the-shelf therapies have attracted much research and investments.

Cytokines, as critical regulators of NK cells, are an appealing choice for cancer immunotherapies, particularly in light of results showing that NK cells strongly rely on type I IFN to initiate an anticancer response (91). However, considerable toxicity and morbidity are associated with direct injection of type I IFN into patients (92), and the focus has moved to strategies that elicit IFN production in the tumor microenvironment using agonists of TLR or the cGAS/STING pathway. 
IL-2 treatment was FDA approved but has also displayed limited clinical efficacy with alarming toxicity, and more recent work focuses on using engineered cytokines and combination therapies (92). For example, treating NK cells with IL-12, IL-18, or the engineered IL-2 cytokine "super-2" (93) increased NK antitumor activity in a mouse model of cancer (94). Additionally, the engineered IL-15 cytokine ALT-803 has shown impressive preclinical results, in part due to its activation of NK cells (95-97). A more comprehensive discussion on cytokine therapy in cancer can be found in a recent review (92).

\section{BiKEs/TriKEs: directing NK cells against cancer}

Antibody therapy also has the appealing advantage of being an off-the-shelf approach to activating NK cells in vivo. In addition to traditional approaches that rely on tumor-binding monoclonal antibodies to activate NK cells via ADCC (17), more recently, bispecific killer cell engagers (BiKEs) have generated great promise. BiKEs are small molecules consisting of two scFvs with different specificity complexed together through flexible linkers (98). One scFv targets a tumor antigen (e.g., CD19, CD20, CD33), while the other is specific for an NK cell receptor (CD16). This effectively brings the cancer and NK cells together, facilitating the formation of an immunological synapse and allowing NK cells to specifically and effectively execute their cytolytic functions (98).

BiKEs' primary target has been CD16, as it potently induces NK activation without additional costimulation $(99,100)$. Preclinically, CD16 BiKEs have been effectively used to target CD19-, CD20-, CD33-, CD133-, and EpCAM-expressing tumor cells (100103). NK cells from myelodysplastic syndrome (MDS) patients could be effectively activated with a CD16-CD33 BiKE targeting not only $\mathrm{CD}_{3} 3^{+} \mathrm{MDS}$ cells but also the immunosuppressive $\mathrm{CD} 33^{+}$ MDSC population (103). In this and other studies, BiKEs were able to redirect autologous NK cells against tumor cells and overcome the immunosuppression prevalent in these conditions (98).

Additional scFvs, such as tri- and tetra-specific killer cell engagers (TriKEs and TetraKEs), can further potentiate therapeutic benefits by targeting more tumor antigens or adding IL-15 into the engager construct. Using an IL-15 cross-linker, Vallera et al. showed that a TriKE targeting CD16 and CD33, namely 161533, induced tumor cell killing more effectively than a CD16-CD33 BiKE in a xenograft model (104). Although the BiKE mediated some early responses, low NK cell proliferation and persistence attributed to lack of the IL-15 linker resulted in relapse, which was not observed with the 161533 TriKE (104). A phase I/II clinical trial of 161533 TriKE for hematologic malignancies will start recruiting in 2020 (NCT03214666). In a recent study, a multifunctional engager targeting CD16 and NKp46 on NK cells and antigens on the tumor cells has shown promising in vitro and in vivo activity (105).

In conclusion, BiKEs and TriKEs provide a non-cell-based immunotherapeutic approach that can harness the patients' own NK cells against cancer. Clinical trials will determine their safety and effectiveness in patients.

\section{Checkpoint receptors on NK cells: breaking barriers}

Immune checkpoint receptors are a group of inhibitory receptors that dampen the effector functions of immune cells. Physiologi- cally, immune checkpoint receptors are essential to prevent autoimmunity and immunopathology, but cancer often exploits them to subvert antitumor immunity (106). Notably, NK cells express many checkpoint receptors, some of which have been targeted by cancer immunotherapy (107).

KIRs and CD94/NKG2A. The majority of KIRs are inhibitory and recognize HLA molecules (108). To replicate missing self recognition, the humanized antagonistic antibody lirilumab (IPH2102) targeting inhibitory KIRs (KIR2DL1-3 and KIR2DS1-2) is in clinical development. In preclinical studies, lirilumab enhances NK-mediated cytotoxicity towards lymphoma, leukemia, and MM (109-111). A phase I trial of lirilumab in MM showed acceptable safety (112), but a phase II trial was halted due to lack of efficacy (113). Interestingly, lack of efficacy was associated with loss of NK cell responsiveness and loss of surface KIR2D expression via trogocytosis (114). Furthermore, while lirilumab treatment was well tolerated, it did not show efficacy in AML in a phase I trial (115), although careful analysis of trends in this trial hinted that optimized dosing may be required (116).

CD94/NKG2A is a heterodimeric inhibitory receptor expressed on NK and T cells that recognizes peptide-bound HLA-E. In both solid tumors and hematological malignancies, HLA-E is upregulated to evade recognition by NK and T cells (117-122), and its expression is associated with poor prognosis (123-125). Two recent preclinical studies blocking NKG2A showed enhanced antitumor immunity by both $\mathrm{T}$ and NK cells in various tumor models (121, 122). A recent preclinical study used protein expression blockers (PEBLs), engineered protein constructs consisting of an $\mathrm{scFv}$ against a target protein that is linked to an ER/Golgi retention peptide to prevent the transport of NKG2A to the cell surface. In this study, PEBLs enhanced NK cell cytotoxicity and antitumor functions (126). Interestingly, preventing NKG2A expression via PEBLs enhanced NK cell in vitro cytotoxicity more than NKG2A antibody blockade. The antagonistic NKG2A antibody monalizumab (IPH2201) is currently under investigation both as a single agent and in combination with cetuximab (anti-EGFR) or durvalumab (anti-PD-L1). Interim results from both combination trials report encouraging safety profiles and signs of efficacy $(121,127)$.

CTLA-4 and PD-1. The first checkpoint receptor targeted for cancer therapy was CTLA-4 $(128,129)$, owing to its important role in suppressing $\mathrm{T}$ cell activation (130). Interestingly, very little research has focused on the role of CTLA- 4 on NK cells. In murine models, CTLA-4 engagement suppressed effector functions of NK cells (131), but the importance of NK cells in mediating the effects of CTLA-4 blockade is still unclear.

PD-1 is the second checkpoint receptor successfully targeted for cancer treatment. PD-1 is an inhibitory receptor with two known ligands: PD-L1 and PD-L2 (132). Multiple approved antibodies target the PD-1/PD-L1 axis in cancer, and their efficacy is attributed to reinvigoration of tumor-targeting $\mathrm{T}$ cells. However, multiple lines of evidence indicate that NK cells play a role in the therapeutic efficacy of PD-1/PD-L1 blockade. Probably the most striking example is Hodgkin lymphoma, which is highly responsive to PD-1 blockade yet exhibits frequent defects in MHC class I presentation, suggesting a $\mathrm{T}$ cell-independent mechanism of action (133-135). Human NK cells from healthy donors and cancer patients express PD-1 (136-139). We and others have found that PD-1+ NK cells 
흘

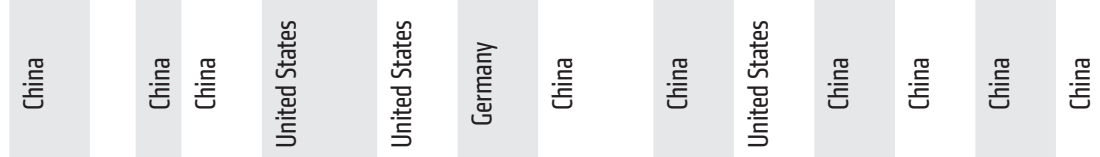

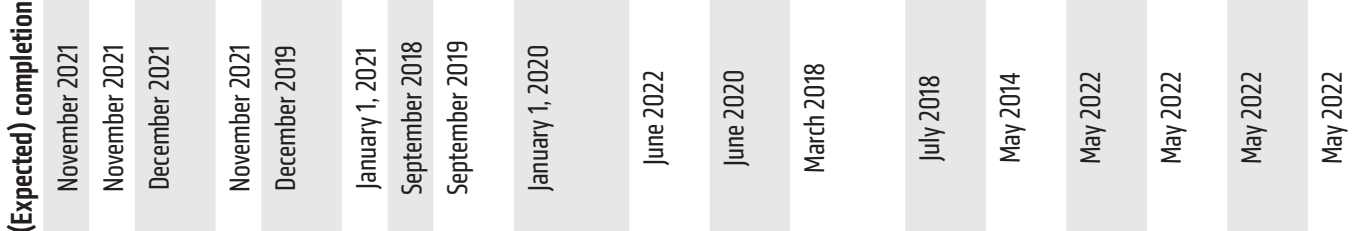

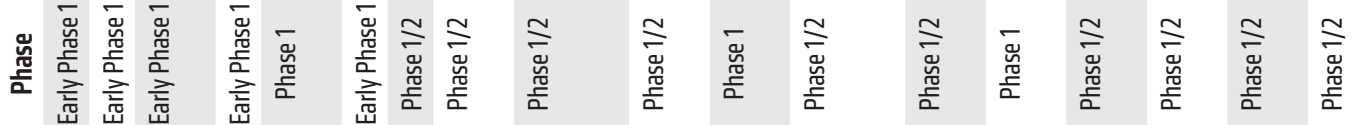

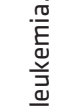

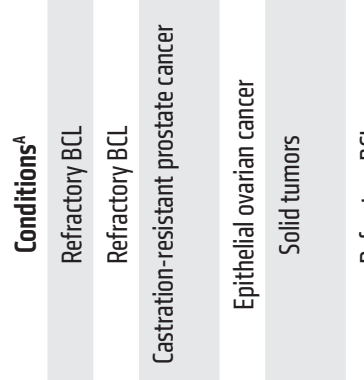

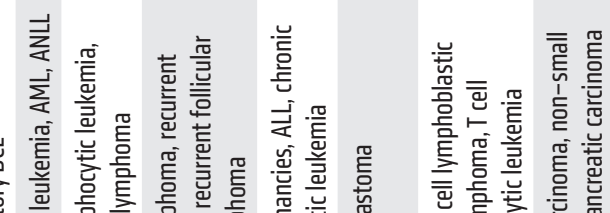

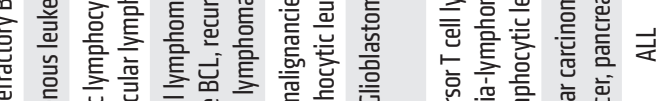

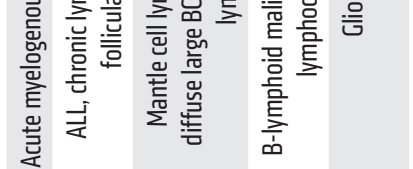

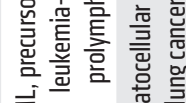

悹

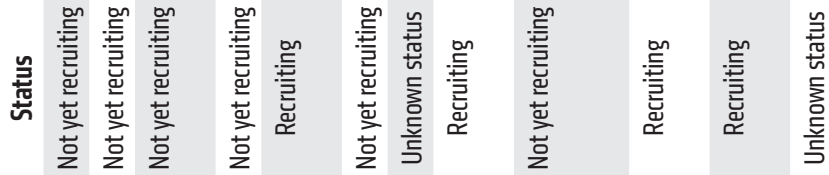

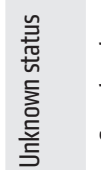

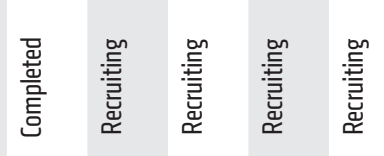

룜

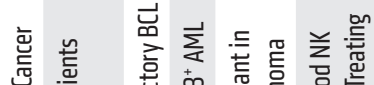

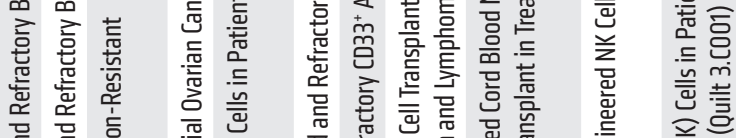

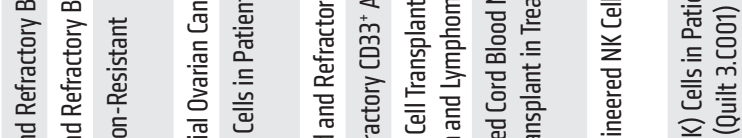

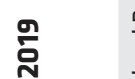

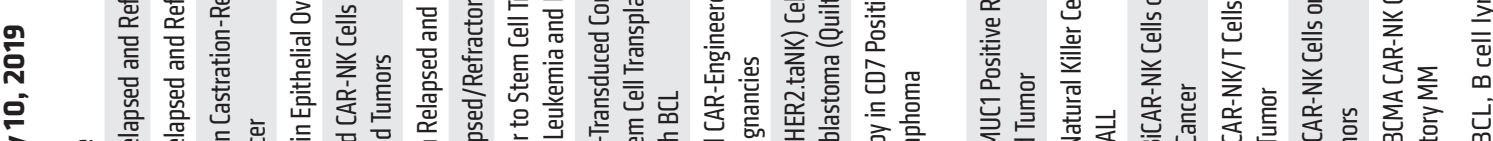

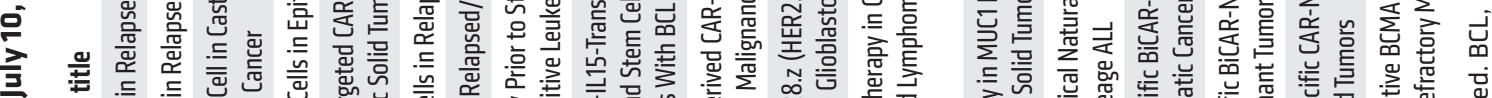

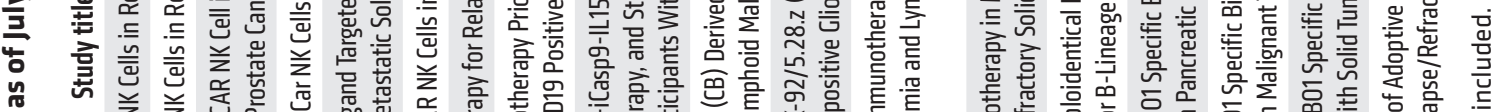

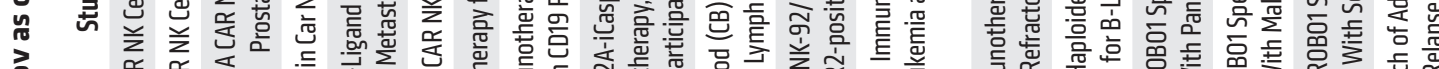

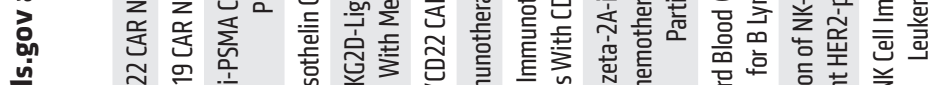

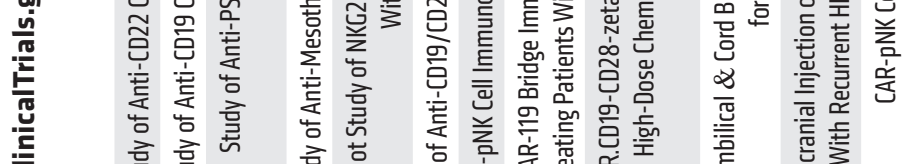

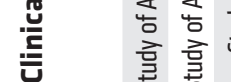

,

㤩密

总

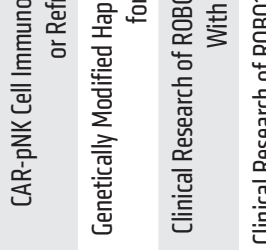

兄要

总

兰

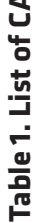
帘

들

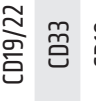

든

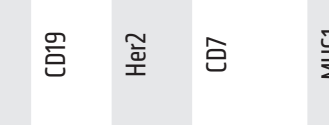


have impaired responses when PD-1 ligands are present but can be re-activated by PD-1/PD-L1 blockade (140-145). To analyze the contribution of NK cells in PD-1/PD-L1 blockade immunotherapy, we employed several murine models of cancer. In leukemia models where cancer cells express low levels of MHC I, and are therefore poor targets for cytotoxic T cells, expression of PD-L1 accelerated tumor growth. PD-1/PD-L1 blockade provided a therapeutic effect that was completely abolished by NK cell depletion. We also determined the contribution of NK cells to PD-L1 blockade in a cancer model where $\mathrm{T}$ cells participated in tumor immune surveillance. Notably, even in this case, NK cells were essential for the full therapeutic effect of PD-L1 blockade (143).

TIGIT. Ligands for the inhibitory receptor TIGIT, CD155 (PVR) and CD112 (PVRL2/Nectin-2), are expressed on many cancer cells (146-148). TIGIT competes for binding to CD155 and CD112 with the receptors DNAM-1 (CD226) and CD96 (Tactile), forming a pathway whereby ligand binding to DNAM-1 delivers an activating signal, while binding to TIGIT or CD96 delivers an inhibitory signal (149). Interestingly, TIGIT blockade results in NK-dependent antitumor immunity in several murine models of cancer (150). TIGIT blockade also enhanced T cell immunity in an NK-dependent manner. Moreover, TIGIT blockade showed synergy with PD-1/PD-L1 blockade, providing rationale for this combination therapy in the clinic. CD96 blockade is less explored, but a recent study targeting this pathway found that this strategy enhanced the antimetastatic properties of NK cells in murine tumor models (151). Further research into combined blockade of TIGIT and CD96 to enhance NK cell antitumor immunity is warranted.

LAG3. LAG3 is an MHC II-binding inhibitory receptor expressed on NK and T cells that has structural homology to CD4 $(152,153)$. Other ligands of LAG3 are LSECtin (154) and FGL1 (155), both of which can be expressed by tumor cells. While LAG3's functions on T cells have been characterized, its role in NK cells is still unclear. NK cells from LAG3-deficient mice displayed impaired cytotoxicity towards some cancer cells, but retained cytotoxicity against MHC I-mismatched cells (156). However, antibody blockade or soluble LAG3 treatment of human NK cells did not impact their cytotoxicity (157). As antibodies targeting LAG3 are currently in clinical evaluation (158), further work on the consequences of LAG3 engagement on NK cells can be expected.

TIM-3. The inhibitory receptor TIM-3 binds to galectin-9, phosphatidylserine, HMGB1, and CEACAM1 (159-162). TIM-3 is constitutively expressed on human NK cells and is upregulated in response to cytokine stimulation $(163,164)$. Like PD-1, TIM-3 expression can mark NK cells that produce IFN- $\gamma$ and release cytotoxic granules as well as NK cells with an exhausted phenotype (164). TIM-3 is upregulated on peripheral NK cells in patients with gastric cancer, lung adenocarcinoma, melanoma, and on tumor-infiltrating NK cells in gastrointestinal stromal tumors (165-168). Importantly, in melanoma and lung adenocarcinoma, TIM-3 blockade enhanced NK cell cytotoxicity and IFN- $\gamma$ production $(165,167)$.

Other checkpoint receptors in NK cells and conclusions. In addition to the checkpoint receptors described above, preclinical research has identified additional negative regulators of NK cell functions, including the negative regulator of cytokine signaling, CIS $(169,170)$, and the high-affinity adenosine receptor $A_{2 A}(171)$.
In summary, these preclinical and clinical studies challenge the dogma that $\mathrm{T}$ cells are the sole mediators of the anticancer effects of checkpoint blockade immunotherapy and highlight the importance of NK cells, which in some cases work in tandem with cytotoxic $\mathrm{T}$ cells and in others play the dominant role. As more targets are discovered, it becomes essential to identify the most effective combination to maximize the therapeutic efficacy of checkpoint blockade on a per-patient basis. Considering the effects of checkpoint blockade on NK cells, they will be of great importance in this process.

\section{NK cells in oncolytic virotherapy}

An alternative to taking off the brakes using checkpoint immunotherapies is to boost NK activation. One successful approach is the use of viruses that specifically infect and lyse cancer cells, broadly referred to as oncolytic viruses (OVs). OVs exploit tumor-specific receptors or observed impairments in infection control in neoplastic cells to selectively infect and replicate in cancer cells, leaving healthy cells unharmed $(172,173)$. It is now clear that OVs' ability to induce a systemic antitumor immune response is perhaps even more critical than their ability to induce direct oncolysis (172, 174). One appealing aspect of OV-based therapy is the ability to engineer delivery of immune-modulating cargos to the tumor microenvironment $(172,174)$. Championing the OV cause, talimogene laherparepvec, an attenuated herpes simplex virus (HSV) expressing GM-CSF, was FDA approved for metastatic melanoma and subsequent studies in combination with checkpoint inhibitors have also indicated remarkable results (174-176). A large number of OVs have now entered clinical trials, and even more are at various stages of preclinical development (Supplemental Table 1; supplemental material available online with this article; https://doi. org/10.1172/JCI129338DS1).

NK cells are evolutionarily designed to detect and eliminate virally infected cells, which can be a detriment for the early OV spread that is necessary for therapeutic purposes (177). In some in vivo models, NK depletion enhanced OV efficacy $(178,179)$, but the majority of studies have illustrated a beneficial or even essential role for NK cells in mediating OV effects (180-184). To explain this dichotomy, an interesting study mathematically modeled the role of NK cells in a treatment regimen of HSV and bortezomib for glioblastoma multiforme. Interestingly, both high and low ratios of NK to cancer cells contributed to enhanced efficacy, while intermediate levels were detrimental. Experimental validation in a glioma PDX model led the authors to speculate that early transient removal of NK cells during viral therapy allows necessary unhindered viral propagation, and subsequent NK adjuvant therapy enhances tumor killing, synergizing with OV therapy (185). This further highlights the importance of considering kinetics in developing combinatorial therapies.

Overall, OV therapy benefits from the innate immune response. In addition to induction of immunogenic cell death, TLR engagement, and release of DAMPs and pathogen-associated molecule patterns (PAMPs) from infected cells $(172,174)$, studies have shown that modulating NK ligand expression on cancer cells following infection drives NK-mediated clearance (186-188). Other studies have uncovered the role of DC-NK cross talk following $\mathrm{OV}$ therapy. We have shown that the Maraba virus directly infects 
A Chemo- and radiotherapy

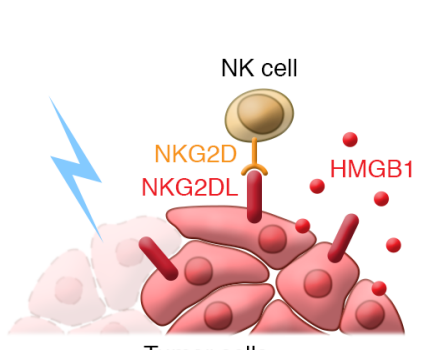

Tumor cells
B Surgery

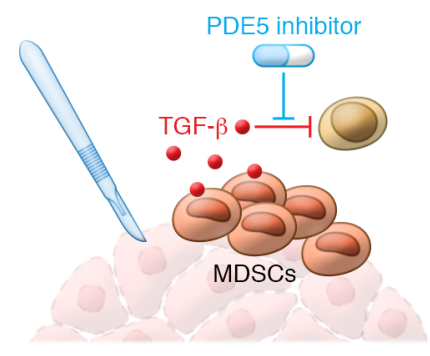

F Adoptive NKs

NK cells from autologous or allogeneic sources
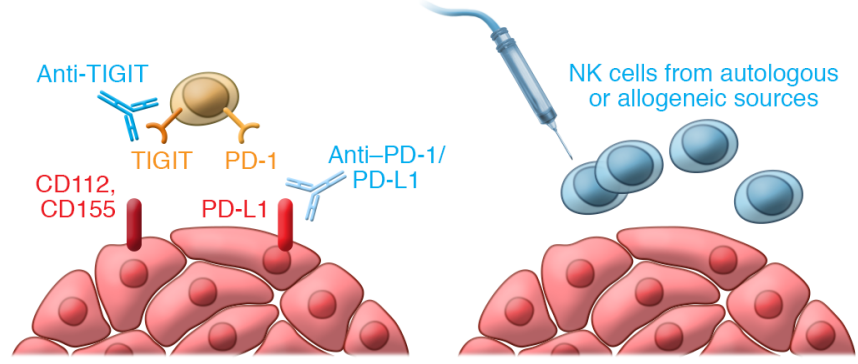

C Oncolytic virotherapy

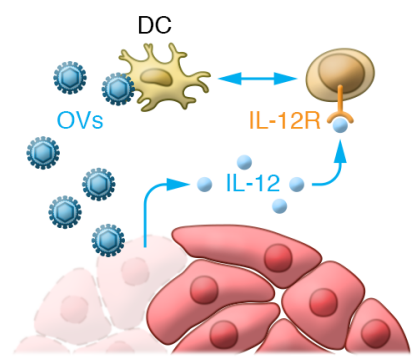

G CAR NKs

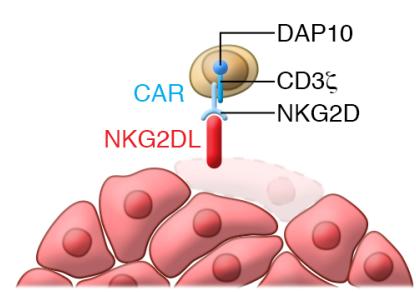

D Engineered cytokines

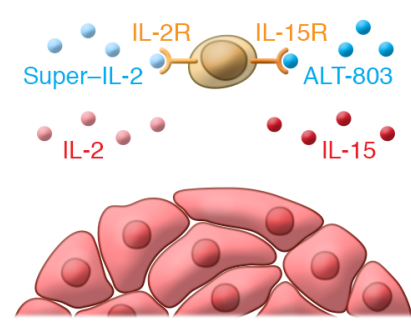

H BiKEs/TriKEs

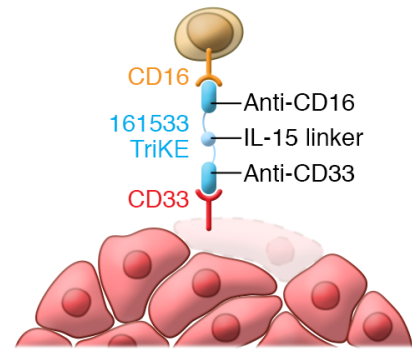

Figure 1. The NK cell armament of cancer immunotherapy: how to harness NK cells against cancer. NK cells kill and eliminate cancer cells, but in the tumor microenvironment they are often insufficiently active or inhibited by immunosuppressive ligands and cytokines. To overcome this, a number of strategies have been developed to enhance NK cell activity against cancer in these settings: (A) Chemo- and radiotherapy induce immunogenic cell death of cancers, leading to expression of NKG2D ligands, HMGB1, and other DAMPs that drive NK cell activation. (B) Surgery leads to the development of an immunosuppressive microenvironment, in part through the expansion of MDSCs and the release of inhibitory cytokines such as TGF- $\beta$. PDE5 inhibitors alongside viral vaccines have proven to be highly effective in reversing this dysfunction. (C) Oncolytic viruses (OVs) infect and lyse cancer cells, but can also infect DCs, leading to their maturation and driving DC-NK cross talk and subsequent NK activation. OVs can also be engineered to deliver cytokines and other immune stimulants to the microenvironment to activate the immune system. (D) Engineered cytokines such as ALT-803, an alternate form of IL-15, have increased potency compared with conventional cytokines. (E) Checkpoint blockers such as anti-PD-1/PD-L1 and anti-TIGIT relinquish NK cells from the immunosuppressive effects exerted by tumors, allowing them to perform their cytolytic functions. (F) NK cells from autologous or allogeneic sources can be safely used as adoptive cell therapy. (C) The use of CARs enhances the efficacy of adoptive therapy. In particular, CARs expressing NKC2D with the $\mathrm{CD} 3 \zeta$ and DAP10 intracellular signaling motifs drive potent antitumor immune responses. (H) BiKEs and TrikEs bring NK cells spatially closer to their targets and activate them. The TriKE 161533 contains a CD16-targeting motif for NK cells, a CD33-targeting motif for cancer cells and MDSCs, and an IL-15 linker to activate NK cells.

conventional DCs (cDCs) and promotes their maturation. Mature cDCs then activate NK cells that better control cancer (189). The centrality of DC-mediated NK activation for OV therapy has also been observed using other oncolytic viruses $(190,191)$.

To further promote antitumor immunity, OVs have been engineered to express NK-stimulating cytokines such as IL-12, IL-15, IL-18, CCL5, and GM-CSF (192-194). Using a similar approach, we developed an NK-activating infected cell vaccine (ICV) based on injection of irradiated autologous tumor cells previously infected ex vivo with a cytokine-expressing OV (195, 196). Using this platform, we showed that an ICV prepared with an IL-12-expressing Maraba virus led to complete regression of established peritoneal tumors in an NK-dependent manner and overcame some of the inherent issues related with in vivo OV infectivity, such as antibody- and complement-mediated neutralization (particularly upon repeated dosing), sequestration by serum proteins, and immune-mediated clearance (196). Additionally, it allows controlled and safe release of potent cytokines at the site of tumor infection. Another cytokine-based approach that has exhibited promising results is the use of a "superago- nist" IL-15, i.e., IL-15 complexed with the $\alpha$ subunit of its receptor (IL-15/IL-15Ra). This approach was shown to increase IL-15's in vivo stability and bioavailability, and a Myxoma virus encoding IL-15/IL-15Ra induced robust NK responses leading to improved outcomes in murine melanoma (197).

As discussed above, surgery can have a major impact on antitumor immunity. As OVs have a strong immunomodulatory potential, we reasoned that virotherapy could recover NK cell dysfunction in tumor models. Indeed, we showed that virotherapy following surgery reduced tumor burden by reverting perioperative NK dysfunction $(50,189)$. We further showed that TLR3 engagement by an inactivated influenza vaccine similarly enhanced NK activity, with additional benefits when MDSC activity was inhibited using a phosphodiesterase 5 (PDE5) inhibitor $(54,198)$. We are currently enrolling patients following major surgical resection of primary abdominal tumors to test a combination of influenza vaccine and PDE5 inhibitor (tadalafil) on NK cell function (NCT02998736). Clearly, OVs can help mitigate surgery-induced dysfunction, but more research is required to evaluate these therapies and find ideal combinations. 
In conclusion, OV-based platforms and combination therapies continue to identify new ways to harness NK cell antitumor activity. Recently, Chen et al. reported promising synergistic results using HSV with an EGFR-targeting CAR-NK to treat breast cancer brain metastasis (199). Following on the heels of bispecific $\mathrm{T}$ cell engagers (BiTEs), potential to engineer BiKEs into OVs is also conceivable (200).

\section{Conclusions and future perspectives: understand to cure}

NK cells are powerful tools in the armamentarium against cancer (Figure 1). They inherently differentiate self from non-self, gauge danger signals on stressed cells, and rapidly eliminate malignant cells, making them an ideal target for cancer immunotherapy. Increasing understanding of the basic mechanisms underlying NK recognition, activation, and suppression fosters incredible excitement and paves the way to immunotherapeutic strategies that elicit NK cell responses against cancer. Valuable preclinical mechanistic research must continue to elucidate the key processes regulating NK cell biology, which will also facilitate clinical translation. One lesson learned from the cancer immunotherapy revolution is that only by understanding the basic biology can one manipulate complex sys- tems, and the dynamic interplay between the immune system and cancer is exquisitely complicated. So far, NK cells have been somehow overlooked as the field has tried to empower $\mathrm{T}$ cell responses against cancer. It is now evident that many immunotherapies thought to elicit $\mathrm{T}$ cell responses also activate NK cells, and that NK cells can be effective in scenarios where T cells fail. For this reason, more research is warranted to accurately and effectively harness the full power of the immune system, including NK cells, against cancer.

\section{Acknowledgments}

We thank Fraser Scott and Seung-Hwan Lee for critically reading this manuscript. JJH is the recipient of a Canadian Institutes of Health Research (CIHR) scholarship. MP is a recipient of a Natural Sciences and Engineering Research Council of Canada (NSERC) scholarship. This work was supported by grants from the CIHR and the Cancer Research Society (CRS) to MA, and grants from the Canadian Cancer Society Research Institute (CCSRI), the Terry Fox Research Institute (TFRI), and CRS to RCA.

Address correspondence to: Michele Ardolino, 501 Smyth Road, Cancer Center, 3-328, Ottawa, Ontario K1H8M2, Canada. Phone: 613.737.8899 ext.77257; Email: m.ardolino@uottawa.ca.
1. Greenberg AH, Playfair JH. Spontaneously arising cytotoxicity to the P-815-Y mastocytoma in NZB mice. Clin Exp Immunol. 1974;16(1):99-109.

2. Herberman RB, Nunn ME, Lavrin DH. Natural cytotoxic reactivity of mouse lymphoid cells against syngeneic acid allogeneic tumors. I. Distribution of reactivity and specificity. Int $J$ Cancer. 1975;16(2):216-229.

3. Kiessling R, Klein E, Wigzell H. "Natural” killer cells in the mouse. I. Cytotoxic cells with specificity for mouse Moloney leukemia cells. Specificity and distribution according to genotype. Eur J Immunol. 1975;5(2):112-117.

4. Freud AG, Mundy-Bosse BL, Yu J, Caligiuri MA. The broad spectrum of human natural killer cell diversity. Immunity. 2017;47(5):820-833.

5. Chiossone L, Chaix J, Fuseri N, Roth C, Vivier $\mathrm{E}$, Walzer T. Maturation of mouse NK cells is a 4-stage developmental program. Blood. 2009;113(22):5488-5496.

6. Stabile H, Fionda C, Gismondi A, Santoni A. Role of distinct natural killer cell subsets in anticancer response. Front Immunol. 2017;8:293.

7. Long EO, Kim HS, Liu D, Peterson ME, Rajagopalan S. Controlling natural killer cell responses: integration of signals for activation and inhibition. Annu Rev Immunol. 2013;31:227-258.

8. Shifrin N, Raulet DH, Ardolino M. NK cell self tolerance, responsiveness and missing self recognition. Semin Immunol. 2014;26(2):138-144.

9. Boudreau JE, Hsu KC. Natural killer cell education and the response to infection and cancer therapy: stay tuned. Trends Immunol. 2018;39(3):222-239.

10. Ljunggren HG, Kärre K. Host resistance directed selectively against $\mathrm{H}$-2-deficient lymphoma variants. Analysis of the mechanism. J Exp Med. 1985;162(6):1745-1759.

11. Kärre K, Ljunggren HG, Piontek G, Kiessling R. Selective rejection of $\mathrm{H}$-2-deficient lymphoma variants suggests alternative immune defence strategy. Nature. 1986;319(6055):675-678.

12. Diefenbach A, Jensen ER, Jamieson AM, Raulet DH. Rae1 and H60 ligands of the NKG2D receptor stimulate tumour immunity. Nature. 2001;413(6852):165-171.

13. Cerwenka A, Baron JL, Lanier LL. Ectopic expression of retinoic acid early inducible-1 gene (RAE-1) permits natural killer cell-mediated rejection of a MHC class I-bearing tumor in vivo. Proc Natl Acad Sci U S A. 2001;98(20):11521-11526.

14. Cerboni C, Zingoni A, Cippitelli M, Piccoli M, Frati L, Santoni A. Antigen-activated human T lymphocytes express cell-surface NKG2D ligands via an ATM/ATR-dependent mechanism and become susceptible to autologous NK- cell lysis. Blood. 2007;110(2):606-615.

15. Ardolino M, et al. DNAM-1 ligand expression on Ag-stimulated T lymphocytes is mediated by ROS-dependent activation of DNA-damage response: relevance for NK-T cell interaction. Blood. 2011;117(18):4778-4786.

16. Thompson TW, et al. Endothelial cells express NKG2D ligands and desensitize antitumor NK responses. Elife. 2017;6:e30881.

17. Guillerey C, Huntington ND, Smyth MJ. Targeting natural killer cells in cancer immunotherapy. Nat Immunol. 2016;17(9):1025-1036.

18. Schleypen JS, et al. Renal cell carcinoma-infiltrating natural killer cells express differential repertoires of activating and inhibitory receptors and are inhibited by specific HLA class I allotypes. Int J Cancer. 2003;106(6):905-912.

19. Carrega P, et al. Natural killer cells infiltrating human nonsmall-cell lung cancer are enriched in CD56 bright CD16(-) cells and display an impaired capability to kill tumor cells. Cancer. 2008;112(4):863-875.

20. Delahaye NF, et al. Alternatively spliced NKp30 isoforms affect the prognosis of gastrointestinal stromal tumors. Nat Med. 2011;17(6):700-707.

21. Chitadze G, Bhat J, Lettau M, Janssen O, Kabelitz D. Generation of soluble NKG2D ligands: proteolytic cleavage, exosome secretion and functional implications. Scand J Immunol. 2013;78(2):120-129.

22. Zingoni A, et al. Targeting NKG2D and NKp30 ligands shedding to improve NK cellbased immunotherapy. Crit Rev Immunol. 2016;36(6):445-460.

23. Ferrari de Andrade L, et al. Antibody-mediated inhibition of MICA and MICB shedding promotes NK cell-driven tumor immunity. Science. 2018;359(6383):1537-1542.

24. Deng W, et al. Antitumor immunity. A shed NKG2D ligand that promotes natural killer cell activation and tumor rejection. Science. 2015;348(6230):136-139.

25. Bi J, Tian Z. NK cell exhaustion. Front Immunol. 2017;8:760.

26. Lee JC, Lee KM, Kim DW, Heo DS. Elevated TGF-beta1 secretion and down-modulation of NKG2D underlies impaired NK cytotoxicity in cancer patients. JImmunol. 2004;172(12):7335-7340.

27 . Viel S, et al. TGF- $\beta$ inhibits the activation and functions of NK cells by repressing the mTOR pathway. Sci Signal. 2016;9(415):ra19.

28. Zaiatz-Bittencourt V, Finlay DK, Gardiner CM Canonical TGF- $\beta$ signaling pathway represses human NK cell metabolism. JImmunol. 2018;200(12):3934-3941.

29. Slattery $\mathrm{K}$, et al. TGF $\beta$ drives mitochondrial dysfunction in peripheral blood NK cells during metastatic breast cancer [preprint]. https://doi.org/10.1101/648501. Posted on bioRxiv May 27, 2019.

30. Cortez VS, et al. SMAD4 impedes the conversion of NK cells into ILC1-like cells by curtailing non-canonical TGF- $\beta$ signaling. Nat Immunol. 2017;18(9):995-1003. 
31. Gao Y, et al. Tumor immunoevasion by the conversion of effector NK cells into type 1 innate lymphoid cells. Nat Immunol. 2017;18(9):1004-1015.

32. Tartter PI, Steinberg B, Barron DM, Martinelli G. The prognostic significance of natural killer cytotoxicity in patients with colorectal cancer. Arch Surg. 1987;122(11):1264-1268.

33. Schantz SP, Campbell BH, Guillamondegui OM. Pharyngeal carcinoma and natural killer cell activity. Am J Surg. 1986;152(4):467-474.

34. Schantz SP, Savage HE, Racz T, Taylor DL, Sacks PG. Natural killer cells and metastases from pharyngeal carcinoma. Am J Surg. 1989;158(4):361-366.

35. Schantz SP, Ordonez NG. Quantitation of natural killer cell function and risk of metastatic poorly differentiated head and neck cancer. Nat Immun Cell Growth Regul. 1991;10(5):278-288.

36. Remark R, et al. Characteristics and clinical impacts of the immune environments in colorectal and renal cell carcinoma lung metastases: influence of tumor origin. Clin Cancer Res. 2013;19(15):4079-4091.

37. Galluzzi L, Zitvogel L, Kroemer G. Immunological mechanisms underneath the efficacy of cancer therapy. Cancer Immunol Res. 2016;4(11):895-902.

38. Spiotto M, Fu YX, Weichselbaum RR. The intersection of radiotherapy and immunotherapy: mechanisms and clinical implications. Sci Immunol. 2016;1(3):EAAG1266.

39. Zingoni A, Fionda C, Borrelli C, Cippitelli M, Santoni A, Soriani A. Natural killer cell response to chemotherapy-stressed cancer cells: role in tumor immunosurveillance. Front Immunol. 2017;8:1194

40. Armeanu S, et al. Natural killer cell-mediated lysis of hepatoma cells via specific induction of NKG2D ligands by the histone deacetylase inhibitor sodium valproate. Cancer Res. 2005;65(14):6321-6329.

41. Soriani A, et al. ATM-ATR-dependent upregulation of DNAM- 1 and NKG2D ligands on multiple myeloma cells by therapeutic agents results in enhanced NK-cell susceptibility and is associated with a senescent phenotype. Blood. 2009;113(15):3503-3511.

42. Fionda C, Soriani A, Malgarini G, Iannitto ML, Santoni A, Cippitelli M. Heat shock protein-90 inhibitors increase MHC class I-related chain A and $\mathrm{B}$ ligand expression on multiple myeloma cells and their ability to trigger NK cell degranulation. J Immunol. 2009;183(7):4385-4394.

43. Fionda $\mathrm{C}$, et al. Inhibition of glycogen synthase kinase-3 increases NKG2D ligand MICA expression and sensitivity to NK cell-mediated cytotoxicity in multiple myeloma cells: role of STAT3. JImmunol. 2013;190(12):6662-6672.

44. Shi J, et al. Bortezomib down-regulates the cell-surface expression of HLA class I and enhances natural killer cell-mediated lysis of myeloma. Blood. 2008;111(3):1309-1317.

45. Fine JH, et al. Chemotherapy-induced genotoxic stress promotes sensitivity to natural killer cell cytotoxicity by enabling missing-self recognition. Cancer Res. 2010;70(18):7102-7113.

46. Guerriero JL, et al. DNA alkylating therapy induces tumor regression through an HMGB1-medi- ated activation of innate immunity. J Immunol. 2011;186(6):3517-3526.

47. Ruscetti M, et al. NK cell-mediated cytotoxicity contributes to tumor control by a cytostatic drug combination. Science. 2018;362(6421):1416-1422.

48. Gasser S, Orsulic S, Brown EJ, Raulet DH. The DNA damage pathway regulates innate immune system ligands of the NKG2D receptor. Nature. 2005;436(7054):1186-1190.

49. Market M, Baxter KE, Angka L, Kennedy MA, Auer RC. The potential for cancer immunotherapy in targeting surgery-induced natural killer cell dysfunction. Cancers (Basel). 2018;11(1):E2 .

50. Tai LH, et al. Preventing postoperative metastatic disease by inhibiting surgery-induced dysfunction in natural killer cells. Cancer Res. 2013;73(1):97-107.

51. Angka L, Khan ST, Kilgour MK, Xu R, Kennedy MA, Auer RC. Dysfunctional natural killer cells in the aftermath of cancer surgery. Int J Mol Sci. 2017;18(8):E1787.

52. Reinhardt R, Pohlmann S, Kleinertz H, Hepner-Schefczyk M, Paul A, Flohé SB. Invasive surgery impairs the regulatory function of human CD56 bright natural killer cells in response to staphylococcus aureus. Suppression of interferon- $\gamma$ synthesis. PLoS ONE. 2015;10(6):e0130155.

53. Angka L, et al. Natural killer cell IFN $\gamma$ secretion is profoundly suppressed following colorectal cancer surgery. Ann Surg Oncol. 2018;25(12):3747-3754

54. Tai LH, et al. Phosphodiesterase-5 inhibition reduces postoperative metastatic disease by targeting surgery-induced myeloid derived suppressor cell-dependent inhibition of natural killer cell cytotoxicity. Oncoimmunology. 2018;7(6):e1431082.

55. Ruggeri L, et al. Role of natural killer cell alloreactivity in HLA-mismatched hematopoietic stem cell transplantation. Blood.1999;94(1):333-339.

56. Ruggeri L, et al. Effectiveness of donor natural killer cell alloreactivity in mismatched hematopoietic transplants. Science. 2002;295(5562):2097-2100.

57. Ruggeri L, et al. Donor natural killer cell allorecognition of missing self in haploidentical hematopoietic transplantation for acute myeloid leukemia: challenging its predictive value. Blood. 2007;110(1):433-440

58. Locatelli F, Pende D, Falco M, Della Chiesa M, Moretta A, Moretta L. NK cells mediate a crucial graft-versus-leukemia effect in haploidentical-HSCT to cure high-risk acute leukemia. Trends Immunol. 2018;39(7):577-590.

59. Mavers M, Bertaina A. High-risk leukemia: Past, present, and future role of NK cells. JImmunol Res. 2018;2018:1586905.

60. Stringaris K, Barrett AJ. The importance of natural killer cell killer immunoglobulin-like receptor-mismatch in transplant outcomes. Curr Opin Hematol. 2017;24(6):489-495

61. Miller JS, et al. Successful adoptive transfer and in vivo expansion of human haploidentical NK cells in patients with cancer. Blood. 2005;105(8):3051-3057.

62. Curti A, et al. Successful transfer of alloreactive haploidentical KIR ligand-mismatched natural killer cells after infusion in elderly high risk acute myeloid leukemia patients. Blood.
2011;118(12):3273-3279.

63. Rubnitz JE, et al. NKAML: a pilot study to determine the safety and feasibility of haploidentical natural killer cell transplantation in childhood acute myeloid leukemia. JClin Oncol. 2010;28(6):955-959.

64. Shah N, et al. Phase I study of cord blood-derived natural killer cells combined with autologous stem cell transplantation in multiple myeloma. Br J Haematol. 2017;177(3):457-466.

65. Parkhurst MR, Riley JP, Dudley ME, Rosenberg SA. Adoptive transfer of autologous natural killer cells leads to high levels of circulating natural killer cells but does not mediate tumor regression. Clin Cancer Res. 2011;17(19):6287-6297.

66. Sakamoto N, et al. Phase I clinical trial of autologous NK cell therapy using novel expansion method in patients with advanced digestive cancer. J Transl Med. 2015;13:277.

67. Geller MA, et al. A phase II study of allogeneic natural killer cell therapy to treat patients with recurrent ovarian and breast cancer. Cytotherapy. 2011;13(1):98-107.

68. Leivas A, et al. Novel treatment strategy with autologous activated and expanded natural killer cells plus anti-myeloma drugs for multiple myeloma. Oncoimmunology. 2016;5(12):e1250051.

69. Denman CJ, et al. Membrane-bound IL-21 promotes sustained ex vivo proliferation of human natural killer cells. PLOS ONE. 2012;7(1):e30264

70. Hsu KC, et al. Improved outcome in HLA-identical sibling hematopoietic stem-cell transplantation for acute myelogenous leukemia predicted by KIR and HLA genotypes. Blood. 2005;105(12):4878-4884.

71. Venstrom JM, et al. KIR and HLA genotypes are associated with disease progression and survival following autologous hematopoietic stem cell transplantation for high-risk neuroblastoma. Clin Cancer Res. 2009;15(23):7330-7334.

72. Tonn $\mathrm{T}$, et al. Treatment of patients with advanced cancer with the natural killer cell line NK-92. Cytotherapy. 2013;15(12):1563-1570.

73. Woll PS, Martin CH, Miller JS, Kaufman DS. Human embryonic stem cell-derived NK cells acquire functional receptors and cytolytic activity. J Immunol. 2005;175(8):5095-5103.

74. Woll PS, et al. Human embryonic stem cells differentiate into a homogeneous population of natural killer cells with potent in vivo antitumor activity. Blood. 2009;113(24):6094-6101.

75. Knorr DA, et al. Clinical-scale derivation of natural killer cells from human pluripotent stem cells for cancer therapy. Stem Cells Transl Med. 2013;2(4):274-283.

76. Zeng J, Tang SY, Toh LL, Wang S. Generation of "off-the-shelf" natural killer cells from peripheral blood cell-derived induced pluripotent stem cells. Stem Cell Reports. 2017;9(6):1796-1812.

77. Jackson HJ, Rafiq S, Brentjens RJ. Driving CAR T-cells forward. Nat Rev Clin Oncol. 2016;13(6):370-383.

78. Locke FL, et al. Phase 1 results of ZUMA-1: A multicenter study of KTE-C19 anti-CD19 CAR T cell therapy in refractory aggressive lymphoma. Mol Ther. 2017;25(1):285-295.

79. Schuster SJ, et al. Tisagenlecleucel in adult relapsed or refractory diffuse large B-cell lym- 
phoma. N Engl J Med.2019;380(1):45-56.

80. Tang X, et al. First-in-man clinical trial of CAR NK-92 cells: safety test of CD33-CAR NK-92 cells in patients with relapsed and refractory acute myeloid leukemia. Am JCancer Res. 2018;8(6):1083-1089.

81. Mehta RS, Rezvani K. Chimeric antigen receptor expressing natural killer cells for the immunotherapy of cancer. Front Immunol. 2018;9:283.

82. Töpfer K, et al. DAP12-based activating chimeric antigen receptor for NK cell tumor immunotherapy. J Immunol. 2015;194(7):3201-3212.

83. Imai C, Iwamoto S, Campana D. Genetic modification of primary natural killer cells overcomes inhibitory signals and induces specific killing of leukemic cells. Blood. 2005;106(1):376-383.

84. Chang YH, Connolly J, Shimasaki N, Mimura K, Kono K, Campana D. A chimeric receptor with NKG2D specificity enhances natural killer cell activation and killing of tumor cells. Cancer Res. 2013;73(6):1777-1786

85. Li Y, Hermanson DL, Moriarity BS, Kaufman DS. Human iPSC-derived natural killer cells engineered with chimeric antigen receptors enhance anti-tumor activity. Cell Stem Cell. 2018;23(2):181-192.e5.

86. Liu E, et al. Cord blood NK cells engineered to express IL-15 and a CD19-targeted CAR show long-term persistence and potent antitumor activity. Leukemia. 2018;32(2):520-531.

87. Siegler EL, Zhu Y, Wang P, Yang L. Off-the-shelf CAR-NK cells for cancer immunotherapy. Cell Stem Cell. 2018;23(2):160-161.

88. Greco R, et al. Improving the safety of cell therapy with the TK-suicide gene. Front Pharmacol. 2015;6:95.

89. Sotillo E, et al. Convergence of acquired mutations and alternative splicing of CD19 enables resistance to CART-19 immunotherapy. Cancer Discov. 2015;5(12):1282-1295.

90. Pettitt D, Arshad Z, Smith J, Stanic T, Holländer G, Brindley D. CAR-T cells: A systematic review and mixed methods analysis of the clinical trial landscape. Mol Ther. 2018;26(2):342-353.

91. Marcus A, Mao AJ, Lensink-Vasan M, Wang L, Vance RE, Raulet DH. Tumor-derived cGAMP triggers a STING-mediated interferon response in non-tumor cells to activate the NK cell response. Immunity. 2018;49(4):754-763.e4.

92. Waldmann TA. Cytokines in cancer immunotherapy. Cold Spring Harb Perspect Biol. 2018;10(12):a028472.

93. Levin AM, et al. Exploiting a natural conformational switch to engineer an interleukin-2 'superkine.' Nature. 2012;484(7395):529-533.

94. Ardolino M, et al. Cytokine therapy reverses NK cell anergy in MHC-deficient tumors. JClin Invest. 2014;124(11):4781-4794.

95. Xu W, et al. Efficacy and mechanism-of-action of a novel superagonist interleukin-15: interleukin-15 receptor $\alpha \mathrm{Su} / \mathrm{Fc}$ fusion complex in syngeneic murine models of multiple myeloma. Cancer Res. 2013;73(10):3075-3086.

96. Kim PS, et al. IL-15 superagonist/IL-15R $\alpha$ Sushi-Fc fusion complex (IL-15SA/IL-15R $\alpha \mathrm{Su}-\mathrm{Fc}$; ALT-803) markedly enhances specific subpopulations of $\mathrm{NK}$ and memory $\mathrm{CD} 8^{+} \mathrm{T}$ cells, and mediates potent anti-tumor activity against murine breast and colon carcinomas. Oncotarget 2016;7(13):16130-16145.

97. Liu B, et al. Evaluation of the biological activities of the IL-15 superagonist complex, ALT-803, following intravenous versus subcutaneous administration in murine models. Cytokine. 2018;107:105-112.

98. Felices M, Lenvik TR, Davis ZB, Miller JS, Vallera DA. Generation of BiKEs and TriKEs to improve NK cell-mediated targeting of tumor cells. Methods Mol Biol. 2016;1441:333-346.

99. Bryceson YT, March ME, Ljunggren HG, Long EO. Synergy among receptors on resting NK cells for the activation of natural cytotoxicity and cytokine secretion. Blood. 2006;107(1):159-166.

100.Gleason MK, et al. Bispecific and trispecific killer cell engagers directly activate human NK cells through CD16 signaling and induce cytotoxicity and cytokine production. Mol Cancer Ther. 2012;11(12):2674-2684 .

101.Vallera DA, et al. Heterodimeric bispecific singlechain variable-fragment antibodies against EpCAM and CD16 induce effective antibodydependent cellular cytotoxicity against human carcinoma cells. Cancer Biother Radiopharm. 2013;28(4):274-282.

102. Wiernik A, et al. Targeting natural killer cells to acute myeloid leukemia in vitro with a CD16 333 bispecific killer cell engager and ADAM17 inhibition. Clin Cancer Res. 2013;19(14):3844-3855.

103. Gleason MK, et al. CD16xCD33 bispecific killer cell engager (BiKE) activates NK cells against primary MDS and MDSC CD $33^{+}$targets. Blood. 2014;123(19):3016-3026.

104.Vallera DA, et al. IL15 trispecific killer engagers (TriKE) make natural killer cells specific to $\mathrm{CD} 33^{+}$targets while also inducing persistence, in vivo expansion, and enhanced function. Clin Cancer Res. 2016;22(14):3440-3450.

105. Gauthier L, et al. Multifunctional natural killer cell engagers targeting NKp46 trigger protective tumor immunity. Cell. 2019;177(7):1701-1713.e16.

106.Wei SC, Duffy CR, Allison JP. Fundamental mechanisms of immune checkpoint blockade therapy. Cancer Discov. 2018;8(9):1069-1086.

107. Muntasell A, et al. Targeting NK-cell checkpoints for cancer immunotherapy. Curr Opin Immunol. 2017;45:73-81.

108.Saunders PM, et al. A bird's eye view of NK cell receptor interactions with their MHC class I ligands. Immunol Rev. 2015;267(1):148-166.

109. Romagné $\mathrm{F}$, et al. Preclinical characterization of 1-7F9, a novel human anti-KIR receptor therapeutic antibody that augments natural killer-mediated killing of tumor cells. Blood. 2009;114(13):2667-2677.

110. Benson DM, et al. IPH2101, a novel anti-inhibitory KIR antibody, and lenalidomide combine to enhance the natural killer cell versus multiple myeloma effect. Blood. 2011;118(24):6387-6391.

111. Kohrt HE, et al. Anti-KIR antibody enhancement of anti-lymphoma activity of natural killer cells as monotherapy and in combination with antiCD20 antibodies. Blood. 2014;123(5):678-686.

112. Benson DM, et al. A phase I trial of the anti-KIR antibody IPH2101 and lenalidomide in patients with relapsed/refractory multiple myeloma. Clin Cancer Res. 2015;21(18):4055-4061.
113. Korde N, et al. A phase II trial of pan-KIR2D blockade with IPH2101 in smoldering multiple myeloma. Haematologica. 2014;99(6):e81-e83.

114. Carlsten M, et al. Checkpoint inhibition of KIR2D with the monoclonal antibody IPH2101 induces contraction and hyporesponsiveness of NK cells in patients with myeloma. Clin Cancer Res. 2016;22(21):5211-5222.

115. Vey N, et al. A phase 1 trial of the anti-inhibitory KIR mAb IPH2101 for AML in complete remission. Blood. 2012;120(22):4317-4323.

116. Chiossone L, Dumas PY, Vienne M, Vivier E. Natural killer cells and other innate lymphoid cells in cancer. Nat Rev Immunol. 2018;18(11):671-688.

117. Lo Monaco E, et al. Human leukocyte antigen E contributes to protect tumor cells from lysis by natural killer cells. Neoplasia. 2011;13(9):822-830.

118. Platonova S, et al. Profound coordinated alterations of intratumoral NK cell phenotype and function in lung carcinoma. Cancer Res. 2011;71(16):5412-5422.

119. Mamessier E, et al. Human breast cancer cells enhance self tolerance by promoting evasion from NK cell antitumor immunity. JClin Invest. 2011;121(9):3609-3622.

120. Ruggeri L, et al. Effects of anti-NKG2A antibody administration on leukemia and normal hematopoietic cells. Haematologica. 2016;101(5):626-633.

121. André P, et al. Anti-NKG2A mAb is a checkpoint inhibitor that promotes anti-tumor immunity by unleashing both $\mathrm{T}$ and NK cells. Cell. 2018;175(7):1731-1743.e13.

122.van Montfoort N, et al. NKG2A blockade potentiates CD8 $\mathrm{T}$ cell immunity induced by cancer vaccines. Cell. 2018;175(7):1744-1755.e15.

123. Gooden M, et al. HLA-E expression by gynecological cancers restrains tumor-infiltrating CD8 ${ }^{+}$T lymphocytes. Proc Natl Acad Sci U S A. 2011;108(26):10656-10661.

124. Bossard C, et al. HLA-E/ $\beta 2$ microglobulin overexpression in colorectal cancer is associated with recruitment of inhibitory immune cells and tumor progression. Int J Cancer. 2012;131(4):855-863.

125. Sun C, et al. High NKG2A expression contributes to NK cell exhaustion and predicts a poor prognosis of patients with liver cancer. Oncoimmunology. 2017;6(1):e1264562.

126. Kamiya T, Seow SV, Wong D, Robinson M, Campana D. Blocking expression of inhibitory receptor NKG2A overcomes tumor resistance to NK cells. J Clin Invest. 2019;130(5):2094-2106.

127. Segal NH, et al. First-in-human dose escalation of monalizumab plus durvalumab, with expansion in patients with metastatic microsatellite-stable colorectal cancer. JClin Oncol. 2018;36(Suppl 15):3540 .

128. Hodi FS, et al. Improved survival with ipilimumab in patients with metastatic melanoma. $N$ Engl J Med.2010;363(8):711-723.

129. Robert C, et al. Ipilimumab plus dacarbazine for previously untreated metastatic melanoma. N Engl JMed. 2011;364(26):2517-2526.

130. Krummel MF, Allison JP. CD28 and CTLA-4 have opposing effects on the response of $\mathrm{T}$ cells to stimulation. J Exp Med. 1995;182(2):459-465.

131. Ni J, Miller M, Stojanovic A, Garbi N, Cerwenka A. Sustained effector function of IL-12/15/18preactivated NK cells against established tumors. 
JExp Med. 2012;209(13):2351-2365.

132. Boussiotis VA. Molecular and biochemical aspects of the PD-1 checkpoint pathway. $N$ Engl $J$ Med. 2016;375(18):1767-1778.

133. Ansell SM, et al. PD-1 blockade with nivolumab in relapsed or refractory Hodgkin's lymphoma. N Engl J Med. 2015;372(4):311-319.

134. Ansell SM. Hodgkin lymphoma: MOPP chemotherapy to PD-1 blockade and beyond. Am J Hematol. 2016;91(1):109-112.

135. Šmahel M. PD-1/PD-L1 blockade therapy for tumors with downregulated MHC class I expression. Int J Mol Sci. 2017;18(6):E1331.

136. Della Chiesa M, et al. Features of memory-like and PD-1(+) human NK cell subsets. Front Immunol. 2016;7:351.

137. Pesce $S$, et al. Identification of a subset of human natural killer cells expressing high levels of programmed death 1: A phenotypic and functional characterization. J Allergy Clin Immunol. 2017;139(1):335-346.e3.

138. Liu Y, et al. Increased expression of programmed cell death protein 1 on NK cells inhibits NK-cell-mediated anti-tumor function and indicates poor prognosis in digestive cancers. Oncogene. 2017;36(44):6143-6153.

139. Mariotti FR, et al. PD-1 in human NK cells: evidence of cytoplasmic mRNA and protein expression. Oncoimmunology. 2019;8(3):1557030.

140. Benson DM, et al. The PD-1/PD-L1 axis modulates the natural killer cell versus multiple myeloma effect: a therapeutic target for CT-011, a novel monoclonal anti-PD-1 antibody. Blood. 2010;116(13):2286-2294.

141. Beldi-Ferchiou A, et al. PD-1 mediates functional exhaustion of activated NK cells in patients with Kaposi sarcoma. Oncotarget. 2016;7(45):72961-72977.

142.Seo H, et al. IL-21-mediated reversal of NK cell exhaustion facilitates anti-tumour immunity in MHC class I-deficient tumours. Nat Commun. 2017;8:15776.

143. Hsu J, et al. Contribution of NK cells to immunotherapy mediated by PD-1/PD-L1 blockade. JClin Invest. 2018;128(10):4654-4668.

144.Concha-Benavente F, Kansy B, Moskovitz J, Moy J, Chandran U, Ferris RL. PD-L1 mediates dysfunction in activated PD-1 $1^{+} \mathrm{NK}$ cells in head and neck cancer patients. Cancer Immunol Res. 2018;6(12):1548-1560.

145. Vari F, et al. Immune evasion via PD-1/PD-L1 on NK cells and monocyte/macrophages is more prominent in Hodgkin lymphoma than DLBCL. Blood.2018;131(16):1809-1819.

146. Bottino C, et al. Identification of PVR (CD155) and Nectin-2 (CD112) as cell surface ligands for the human DNAM-1 (CD226) activating molecule. J Exp Med. 2003;198(4):557-567.

147. Iguchi-Manaka A, et al. Accelerated tumor growth in mice deficient in DNAM-1 receptor. JExp Med. 2008;205(13):2959-2964.

148. Casado JG, et al. Expression of adhesion molecules and ligands for activating and costimulatory receptors involved in cell-mediated cytotoxicity in a large panel of human melanoma cell lines. Cancer Immunol Immunother. 2009;58(9):1517-1526.

149. Huntington ND, Martinet L, Smyth MJ. DNAM-1: would the real natural killer cell please stand up!
Oncotarget. 2015;6(30):28537-28538.

150.Zhang Q, et al. Blockade of the checkpoint receptor TIGIT prevents NK cell exhaustion and elicits potent anti-tumor immunity. Nat Immunol. 2018;19(7):723-732.

151. Roman Aguilera A, et al. CD96 targeted antibodies need not block CD96-CD155 interactions to promote NK cell anti-metastatic activity. Oncoimmunology. 2018;7(5):e1424677.

152. Triebel F, et al. LAG-3, a novel lymphocyte activation gene closely related to CD4. JExp Med. 1990;171(5):1393-1405.

153. Huard B, Prigent P, Tournier M, Bruniquel D, Triebel F. CD4/major histocompatibility complex class II interaction analyzed with CD4- and lymphocyte activation gene-3 (LAG-3)-Ig fusion proteins. Eur JImmunol. 1995;25(9):2718-2721.

154.Xu F, et al. LSECtin expressed on melanoma cells promotes tumor progression by inhibiting antitumor T-cell responses. Cancer Res. 2014;74(13):3418-3428.

155. Wang J, et al. Fibrinogen-like protein 1 is a major immune inhibitory ligand of LAG-3. Cell. 2019;176(1-2):334-347.e12.

156. Miyazaki T, Dierich A, Benoist C, Mathis D. Independent modes of natural killing distinguished in mice lacking Lag3. Science. 1996;272(5260):405-408.

157. Huard B, Tournier M, Triebel F. LAG-3 does not define a specific mode of natural killing in human. Immunol Lett. 1998;61(2-3):109-112.

158. Andrews LP, Marciscano AE, Drake CG, Vignali DA. LAG3 (CD223) as a cancer immunotherapy target. Immunol Rev. 2017;276(1):80-96.

159. Zhu C, et al. The Tim-3 ligand galectin-9 negatively regulates $\mathrm{T}$ helper type 1 immunity. Nat Immunol. 2005;6(12):1245-1252.

160. DeKruyff RH, et al. T cell/transmembrane, Ig, and mucin-3 allelic variants differentially recognize phosphatidylserine and mediate phagocytosis of apoptotic cells. J Immunol. 2010;184(4):1918-1930.

161. Chiba S, et al. Tumor-infiltrating DCs suppress nucleic acid-mediated innate immune responses through interactions between the receptor TIM-3 and the alarmin HMGB1. Nat Immunol. 2012;13(9):832-842.

162. Huang YH, et al. CEACAM1 regulates TIM-3mediated tolerance and exhaustion. Nature. 2015;517(7534):386-390.

163. Gleason MK, et al. Tim-3 is an inducible human natural killer cell receptor that enhances interferon gamma production in response to galectin-9. Blood. 2012;119(13):3064-3072.

164. Ndhlovu LC, et al. Tim-3 marks human natural killer cell maturation and suppresses cell-mediated cytotoxicity. Blood. 2012;119(16):3734-3743.

165. da Silva IP, et al. Reversal of NK-cell exhaustion in advanced melanoma by Tim-3 blockade. Cancer Immunol Res. 2014;2(5):410-422.

166. Wang $Z$, et al. The clinical significance of abnormal Tim-3 expression on NK cells from patients with gastric cancer. Immunol Invest. 2015;44(6):578-589.

167. Xu L, et al. Increased Tim-3 expression in peripheral NK cells predicts a poorer prognosis and Tim-3 blockade improves NK cell-mediated cytotoxicity in human lung adenocarcinoma. Int
Immunopharmacol. 2015;29(2):635-641.

168. Komita H, et al. Expression of immune checkpoint molecules of $\mathrm{T}$ cell immunoglobulin and mucin protein 3/galectin-9 for NK cell suppression in human gastrointestinal stromal tumors. Oncol Rep. 2015;34(4):2099-2105.

169. Delconte RB, et al. CIS is a potent checkpoint in NK cell-mediated tumor immunity. Nat Immunol. 2016;17(7):816-824.

170.Rautela J, Surgenor E, Huntington N. Efficient genome editing of human natural killer cells by CRISPR RNP [preprint]. https://www.biorxiv. org/content/10.1101/406934v1. Posted on bioRxiv September 6, 2018.

171. Mittal D, et al. Antimetastatic effects of blocking $\mathrm{PD}-1$ and the adenosine A2A receptor. Cancer Res. 2014;74(14):3652-3658.

172. Aitken AS, Roy DG, Bourgeois-Daigneault MC. Taking a stab at cancer; oncolytic virus-mediated anti-cancer vaccination strategies. Biomedicines. 2017;5(1):E3.

173. Twumasi-Boateng K, Pettigrew JL, Kwok YYE, Bell JC, Nelson BH. Oncolytic viruses as engineering platforms for combination immunotherapy. Nat Rev Cancer. 2018;18(7):419-432.

174. Andtbacka RH, et al. Talimogene laherparepvec improves durable response rate in patients with advanced melanoma. JClin Oncol. 2015;33(25):2780-2788.

175. Ribas A, et al. Oncolytic virotherapy promotes intratumoral $\mathrm{T}$ cell infiltration and improves anti-PD-1 immunotherapy. Cell. 2017;170(6):1109-1119.e10.

176. Chesney J, et al. Randomized, open-label phase II study evaluating the efficacy and safety of talimogene laherparepvec in combination with ipilimumab versus ipilimumab alone in patients with advanced, unresectable melanoma. JClin Oncol. 2018;36(17):1658-1667.

177. Bhat R, Rommelaere J. Emerging role of natural killer cells in oncolytic virotherapy. Immunotargets Ther. 2015;4:65-77.

178. Altomonte J, et al. Exponential enhancement of oncolytic vesicular stomatitis virus potency by vector-mediated suppression of inflammatory responses in vivo. Mol Ther. 2008;16(1):146-153.

179. Alvarez-Breckenridge CA, et al. NK cells impede glioblastoma virotherapy through $\mathrm{NKp} 30$ and NKp46 natural cytotoxicity receptors. Nat Med. 2012;18(12):1827-1834.

180. Miller CG, Fraser NW. Requirement of an integrated immune response for successful neuroattenuated HSV-1 therapy in an intracranial metastatic melanoma model. Mol Ther. 2003;7(6):741-747.

181. Wongthida $\mathrm{P}$, et al. Type III IFN interleukin-28 mediates the antitumor efficacy of oncolytic virus VSV in immune-competent mouse models of cancer. Cancer Res. 2010;70(11):4539-4549.

182. Ogbomo H, et al. Tumor cells infected with oncolytic influenza A virus prime natural killer cells for lysis of resistant tumor cells. Med Microbiol Immunol. 2010;199(2):93-101.

183. Miyamoto S, et al. Coxsackievirus B3 is an oncolytic virus with immunostimulatory properties that is active against lung adenocarcinoma. Cancer Res. 2012;72(10):2609-2621.

184. Ogbomo H, et al. Myxoma virus infection promotes NK lysis of malignant gliomas in vitro and 
in vivo. PLoS ONE. 2013;8(6):e66825.

185. Kim Y, et al. Complex role of NK cells in regulation of oncolytic virus-bortezomib therapy. Proc Natl Acad Sci U S A. 2018;115(19):4927-4932.

186.Jarahian M, et al. Activation of natural killer cells by newcastle disease virus hemagglutinin-neuraminidase. J Virol. 2009;83(16):8108-8121.

187. Bhat R, Dempe S, Dinsart C, Rommelaere J. Enhancement of NK cell antitumor responses using an oncolytic parvovirus. Int J Cancer. 2011;128(4):908-919.

188. Bhat R, Rommelaere J. NK-cell-dependent killing of colon carcinoma cells is mediated by natural cytotoxicity receptors (NCRs) and stimulated by parvovirus infection of target cells. BMC Cancer. 2013;13:367.

189.Zhang J, et al. Maraba MG1 virus enhances natural killer cell function via conventional dendritic cells to reduce postoperative metastatic disease. Mol Ther. 2014;22(7):1320-1332.

190.Errington F, et al. Reovirus activates human dendritic cells to promote innate antitumor immuni- ty. JImmunol. 2008;180(9):6018-6026.

191. Boudreau JE, et al. Recombinant vesicular stomatitis virus transduction of dendritic cells enhance their ability to prime innate and adaptive antitumor immunity. Mol Ther. 2009;17(8):1465-1472.

192.Lapteva N, et al. Targeting the intratumoral dendritic cells by the oncolytic adenoviral vaccine expressing RANTES elicits potent antitumor immunity. J Immunother. 2009;32(2):145-156. 193. Stephenson KB, Barra NG, Davies E, Ashkar AA, Lichty BD. Expressing human interleukin-15 from oncolytic vesicular stomatitis virus improves survival in a murine metastatic colon adenocarcinoma model through the enhancement of anti-tumor immunity. Cancer Gene Ther. 2012;19(4):238-246.

194. Choi KJ, Zhang SN, Choi IK, Kim JS, Yun CO. Strengthening of antitumor immune memory and prevention of thymic atrophy mediated by adenovirus expressing IL-12 and GM-CSF. Gene Ther. 2012;19(7):711-723.

195.Lemay CG, et al. Harnessing oncolytic virus- mediated antitumor immunity in an infected cell vaccine. Mol Ther. 2012;20(9):1791-1799.

196. Alkayyal AA, et al. NK-cell recruitment is necessary for eradication of peritoneal carcinomatosis with an IL12-expressing Maraba virus cellular vaccine. Cancer Immunol Res. 2017;5(3):211-221.

197. Tosic V, et al. Myxoma virus expressing a fusion protein of interleukin-15 (IL15) and IL15 receptor alpha has enhanced antitumor activity. PLoS ONE. 2014;9(10):e109801.

198. Tai LH, et al. Perioperative influenza vaccination reduces postoperative metastatic disease by reversing surgery-induced dysfunction in natural killer cells. Clin Cancer Res. 2013;19(18):5104-5115.

199. Chen X, et al. A combinational therapy of EGFRCAR NK cells and oncolytic herpes simplex virus 1 for breast cancer brain metastases. Oncotarget. 2016;7(19):27764-27777.

200.Speck T, et al. Targeted BiTE expression by an oncolytic vector augments therapeutic efficacy against solid tumors. Clin Cancer Res. 2018;24(9):2128-2137. 